\title{
Professor Hans-Joachim Schmoll - 10 Years Editor-in-Chief of OnKologie
}

\author{
Michael Hallek \\ Klinik I für Innere Medizin, der Universität zu KöIn, Germany
}

In 2002 Hans-Joachim Schmoll (Halle) took over the position of Editor-in-Chief of the journal ONKOLOGIE from his predecessor Wolfgang Queißer (Mannheim). With the beginning of the year 2013 he will resign from this office. It is therefore more than appropriate to take this opportunity to thank him for over one decade of excellent work in this honorary position, in which he set an outstandingly successful course for the development of ONKOLOGIE.

During his term of office the number of annually submitted manuscripts increased from about 120 to more than 300. Consequently, the selection of manuscripts grew continuously stricter and the rejection rate rose from $20 \%$ to $73 \%$, enabling a constant improvement of scientific quality. The impact factor, in 2002 at 0.855 , had reached in the meantime 1.724 . Main innovations during this time were the implementation of the online manuscript submission and peer review in 2004 that tremendously improved the review times, the increase from 6 to 12 issues per year that led to shorter publication times, and the introduction of international editorials that firmly established the journal in the international research community. Owing to these developments OnKOLOGIE is internationally renowned and as the official organ of many oncological societies, especially in the German-speaking countries, a constant of the oncological publication landscape.

In Hans-Joachim Schmoll OnKologie had not only a dedicated but also an internationally well-respected oncologist as its editor. He is member of numerous scientific societies and over the years he has held key positions in many of them among others in the German Arbeitsgemeinschaft Internistische Onkologie (AIO) of the German Cancer Society to the
European Organisation for Research and Treatment of Cancer (EORTC) or the American Society of Clinical Oncology (ASCO).

Like nobody else in Germany he stands for medical oncology and patient-oriented clinical research. His dedication to this and the advancement of oncological research has not only brought him the gratitude of his patients but also a high reputation among his colleagues, both nationally and internationally. He is the editor of more than 15 books; however, in the German-speaking countries he is best known as editor of 'Kompendium Internistische Onkologie' (together with Professors Höffken and Possinger). This exemplary reference book is also known in short as 'The Schmoll'. It has certainly helped generations of medical oncologists in their education and training and has furthermore had an integrating and in the best sense standardizing effect on the whole discipline of medical oncology, including the treatment of hematological neoplasias. Internationally Hans-Joachim Schmoll is known for his scientific publications in high-ranking journals on the development of efficient combination therapies for colorectal carcinoma. - To date, he has published more than 350 articles in peer reviewed journals. As member of the editorial board of numerous journals, including Journal of Clinical Oncology, Cancer Research, European Journal of Cancer, Annals of Oncology, Critical Reviews in Hematology and Oncology, and Cancer \& Chemotherapy Reviews, he has certainly left his mark on the scientific landscape. He used this reputation to advocate the progress of OnKOLOGIE; for this, Karger publishers but also the field of medical oncology are much indebted to him.

Cologne, December 2012 Michael Hallek

\section{KARGER \\ Fax +49 7614520714 \\ Information@Karger.de}

www.karger.com (c) 2012 S. Karger GmbH, Freiburg

0378-584X/12/3512-0728\$38.00/0

Accessible online at:

www.karger.com/onk
Prof. Dr. med. Michael Hallek

Klinik I für Innere Medizin

der Universität zu Köln

Kerpener Str. 62, 50937 Köln

michael.hallek@uni-koeln.de 